\title{
RESEARCH
}

\section{Current Practices of Awarding Graduation Honors within Doctor of Pharmacy Degree Programs}

\author{
Paul A. DiPietro, ${ }^{a}$ Stacy L. Longo, ${ }^{a}$ Beth E. Welch, PharmD, ${ }^{a}$ Daniel R. Kennedy, PhD, ${ }^{a}$ \\ Eric C. Nemec, PharmD, MEHP \\ ${ }^{\text {a }}$ Western New England University College of Pharmacy, Springfield, Massachusetts \\ ${ }^{\mathrm{b}}$ Sacred Heart University, Fairfield, Connecticut \\ Submitted December 4, 2015; accepted February 11, 2016; published May 2017.
}

\begin{abstract}
Objective. To survey the practices of awarding honors upon graduation with a doctor of pharmacy degree.

Methods. College and school of pharmacy websites were systematically searched to identify if, and then how, graduation honors are awarded. Programs that offer graduation honors were categorized and quantified based upon grade point average (GPA) cutoffs, honors enrollment, research project completion, faculty vote, course failure considerations, and ethics code violations.

Results. Of the 132 doctor of pharmacy programs reviewed, $86 \%(n=114)$ had accessible online resources and were included in data analysis. Of these 114 programs, $43 \%(n=49)$ award honors upon graduation, and 57\% $(n=65)$ do not. Among the 49 programs that award honors, 30 award the Latin honors. Of the remaining 19 programs, 18 award alternative graduation honors, and one awards both. Conclusions. Latin honors are the most common form of graduation honors utilized by doctor of pharmacy programs that award honors upon graduation. There is a variety of GPA cutoffs utilized across programs.
\end{abstract}

Keywords: graduation honors, assessment

\section{INTRODUCTION}

Graduation honors, in their historical context, are commonly referred to as "Latin honors" (ie, cum laude, magna cum laude, and summa cum laude). The practice of awarding these graduation honors, which began in undergraduate programs, now also is found in many levels of post-secondary education, including health professions such as pharmacy, nursing, and medical school. ${ }^{1,2}$ It is unknown to what extent graduation honors are utilized in health professional education programs, nor the achievements required to attain them. This paper seeks to fill the knowledge void in pharmacy education regarding the practice of awarding graduation honors.

Graduation honors are thought to serve as a method of motivation, distinction, and commendation for superior performance. There are some small studies that indicate undergraduate honors program completers have the highest academic performance, best graduation rates, and shortest

Corresponding Author: Eric C. Nemec, Sacred Heart University, 5151 Park Ave., Fairfield, CT. Tel: 203-989-9232. Fax: 413-796-2266. E-mail: nemece@sacredheart.edu Note: At the time of manuscript submission, Eric C. Nemec was affiliated with Western New England University College of Pharmacy in Springfield, Massachusetts. time to degree completion. However, a review of the literature yielded limited data that examined the impact of graduation honors on student achievement, satisfaction, or career disposition. ${ }^{3,4}$ One study conducted in medical students examined their perceptions of an honors system in connection with a revised curriculum. Valid concerns were raised by the authors regarding whether an honors system contradicted the principles of adult learning, where students theoretically respond more to internal motivation rather than external. ${ }^{5}$ The results of their survey showed that the students were in favor of retaining the honors system for the purpose of motivation. Interestingly, students in the later years of the curriculum thought that the honors system may act as a demotivator to learning and have a negative impact on group work. ${ }^{5}$

Faculty in this study felt that honors provided three benefits, a motivation for learning, a marker of distinction, and as a bargaining chip for residency placement. ${ }^{5}$ In contrast, other research identified that many medical students thought that academic awards were only mildly or not important for residency placement, but put more weight on honors grades received during clinical education. ${ }^{6}$ It is unclear in professional pharmacy education if graduation honors fulfill these purposes. Moreover, there exists no data regarding medical, nursing, dental, or other health care professional program that quantitatively describes honors 


\section{American Journal of Pharmaceutical Education 2017; 81 (4) Article 69.}

practices within their respective academies. Among undergraduate education, the awarding of graduation honors appears to be very common, while the prevalence is largely unknown among professional doctorate level education, such as in a doctor of pharmacy program.

Within pharmacy education, there is no known standard for the awarding of graduation honors, nor criteria for doing such. Additionally, literature pertaining to graduation honors in doctor of pharmacy degree programs is nonexistent. The analysis of performance associated with a particular grade point average only carries true validity when compared internally; that is, compared with students from the same program. ${ }^{7,8}$ Comparing performance externally, or with students across different programs, carries no validity because of the variability associated with the content and grading scale utilized, even despite the fact that quantitative parameters, such as GPA and class rank, are the standards that have largely been utilized by pharmacy employers and residency directors to distinguish between applicants. ${ }^{9-13}$

This novel research project aims to provide insight into the practices of awarding graduation honors among doctor of pharmacy degree programs. Understanding the current practices of awarding graduation honors in doctor of pharmacy programs may help to more clearly define what exactly graduation honors mean in the context of doctor of pharmacy education, and can provide a framework for considerations regarding graduation honors criteria and eventually establishing a standard.

\section{METHODS}

From December 2014 to January 2015, the websites of the 132 US pharmacy programs with at least pre-candidate status from the Accreditation Council of Pharmacy Education (ACPE) were systematically searched for program catalogs, student handbooks, and/or academic bulletins in order to identify if and how graduation honors are awarded. Out of these 132 programs, 114 (86\%) were identified as having available website information that specified the presence or absence of graduation honors. The remaining 18 programs lacked adequate website materials to establish their graduation honors practices. Programs that offered graduation honors were categorized and quantified based upon GPA cutoffs, honors enrollment, research project completion, faculty vote, course failure considerations, and ethics code violations. Programs also were categorized and quantified based on the type of honors awarded, such as Latin honors or alternative honors designations.

\section{RESULTS}

Of the 114 doctor of pharmacy programs that were identified as having an available online resource that specified the presence or absence of graduation honors, $43 \%(n=49)$ awarded graduation honors and $57 \%(n=65)$ did not award graduation honors (Figure 1). When broken down by institution type, either public or private status, there was no significant difference with regards to the practice of awarding honors (Table 1). Further stratification based upon average graduating class size, again revealed no significant trend with respect to graduation honors (Table 2). Of note, only $10 \%$ of three-year private programs awarded graduation honors. Each region of the country was adequately represented among the 49 programs that awarded graduation honors, thus alleviating any geographic pattern that may or may not be present.

Of the 49 doctor of pharmacy programs that awarded graduation honors, $61 \%(n=30)$ used Latin honors based on GPA cutoffs (Figure 1). For programs that awarded alternative graduation honors, there was significant variation with respect to the criteria utilized in considering eligibility. Similarly, there was variance among the cutoffs utilized in programs that use GPA as criteria for graduation honors. Interestingly, despite this variance, the mean GPA cutoffs for Latin honors still appeared to be nearly reflective of the most frequently utilized cutoffs, often just below the mode values because of low end outliers (Table 3 ). With respect to identified outliers, very few fell outside 2 standard deviations above or below the mean.

A nominal number of programs $(n=7)$ utilize class rank for awarding graduation honors rather than grade point average. Among these seven programs, there were differences with regards to the semantics used to identify the honors However, there was general consistency with regards to the benchmarks utilized for the rank requirement. Schools that employed class rank had a variety of honors tiers, ranging anywhere from one tier where the top $5 \%$ graduated with honors, to a three-tiered system where students who were in the top 5\%,10\%, and $20 \%$ received graduation honors. Some of these programs instituted a minimum GPA requirement for students to be eligible.

A total of 12 doctor of pharmacy programs included "other" considerations (Table 4) for awarding honors in conjunction with either Latin or alternative honors. Examples of alternatives to Latin honors included graduation with honors, high honors, graduation with special distinction, with distinction, with high distinction, and with highest distinction. Doctor of pharmacy candidates graduating from these programs must fulfill additional requirements in addition to obtaining a minimum GPA or specific class rank, and in some instances programs require two or even three of these "other" considerations to be met in addition to the traditional GPA or class rank requirements. These considerations include requirement of a thesis $(n=1)$, a research project $(n=3)$, or enrollment 


\section{American Journal of Pharmaceutical Education 2017; 81 (4) Article 69.}

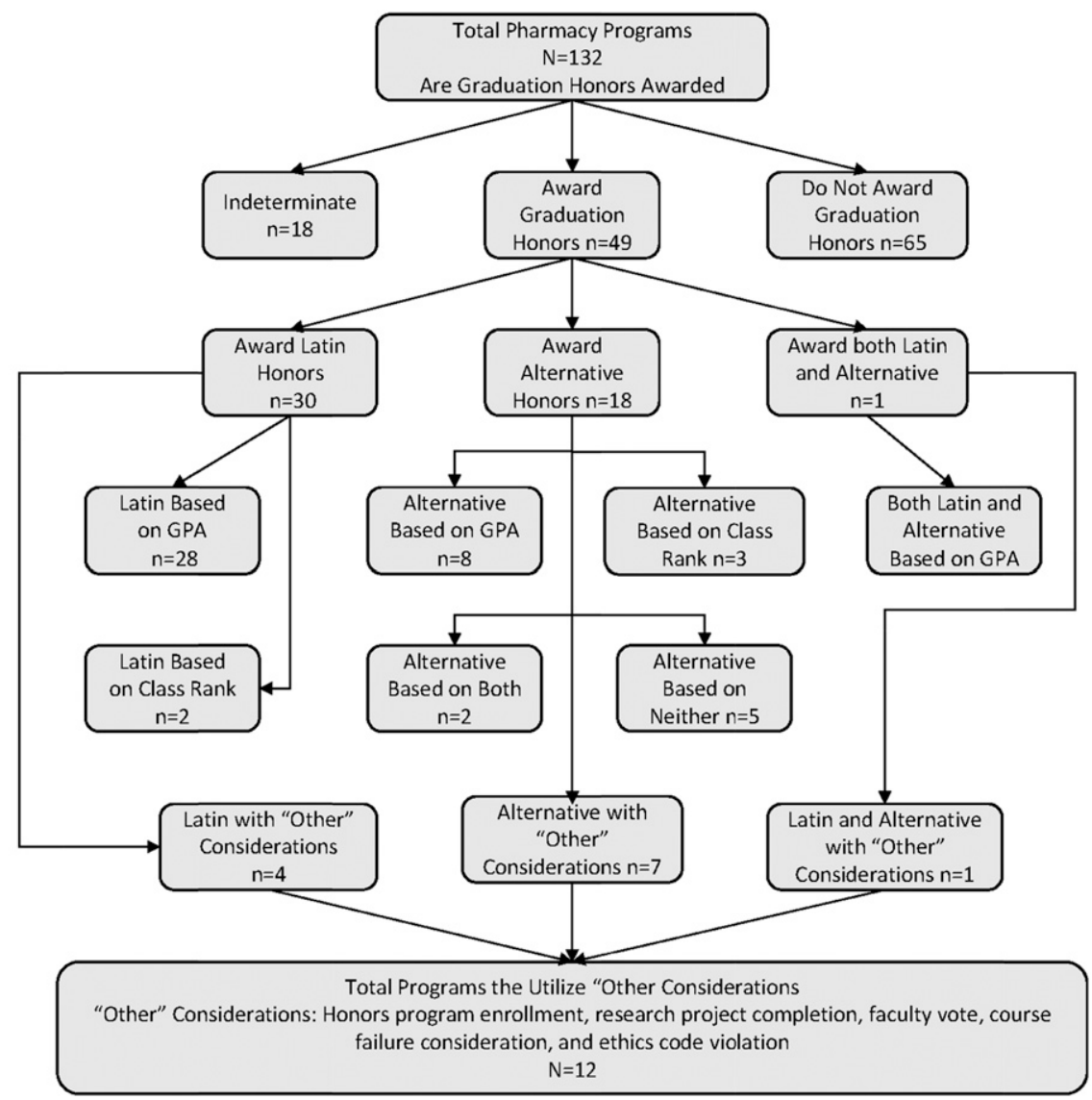

Figure 1. Doctor of Pharmacy Degree Program Graduation Honors Classification.

in an honors college $(n=5)$. Additionally, some programs include exclusion criteria. For example, two programs have a provision to exclude one's eligibility based on previous course failure, three programs employ a provision to exclude graduates with an ethics violation in their record, and four programs allow for faculty to vote on a student's eligibility to receive graduation honors. Utilizing faculty vote as an "other" requirement for the receipt of graduation honors represents a more subjective criteria than is typically seen among honors criteria. However, it was still the second most prevalent "other" consideration.

\section{DISCUSSION}

The results of this research illustrate that across doctor of pharmacy programs, there is no common established criteria across all programs regarding the practice of awarding graduation honors. The data collected in this

Table 1 . Honors by Institution Type $(\mathrm{N}=114)$

\begin{tabular}{lcc}
\hline & Honors \% (n) & No Honors \% (n) \\
\hline Public Schools & $44.3(27)$ & $55.7(34)$ \\
Private Schools & $41.5(22)$ & $58.5(31)$ \\
\hline
\end{tabular}

research only represent the status of graduation honors at a single point in time and therefore, without the presence of historical data, this research cannot be extrapolated to identify any sort of trends that may exist regarding an increase or decrease in the implementation of graduation honors in doctor of pharmacy programs. The question that remains to be answered is whether or not doctor of pharmacy degree programs and their learners receive benefit from a graduation honors program. Thus, clarity regarding what exactly graduation honors mean in the context of pharmacy education is needed.

While a majority of the identified programs that award graduation honors utilize Latin honors (61\%), many programs (37\%) utilize some form of alternative

Table 2. Honors by Class Size $(\mathrm{N}=114)$

\begin{tabular}{lcc}
\hline Class size & Honors \% (n) & No Honors \% (n) \\
\hline$<50$ & $4.1(2)$ & $3.1(2)$ \\
$50-100$ & $40.8(20)$ & $47.7(31)$ \\
$101-150$ & $30.6(15)$ & $27.7(18)$ \\
$151-200$ & $12.2(6)$ & $13.8(9)$ \\
$>201$ & $12.2(6)$ & $7.7(5)$ \\
\hline
\end{tabular}




\section{American Journal of Pharmaceutical Education 2017; 81 (4) Article 69.}

Table 3. Latin Honors Cutoff $(n=30)$

\begin{tabular}{lcccc}
\hline & Mean GPA (SD) & Mode GPA & \# Schools + 2SD & \# Schools -2SD \\
\hline Cum Laude & $3.5(0.1)$ & 3.5 & 1 & 1 \\
Magna Cum Laude & $3.7(0.05)$ & 3.7 & 2 & 2 \\
Summa Cum Laude & $3.9(0.0709)$ & 3.9 & 0 & 1 \\
\hline
\end{tabular}

honors. It is important to recognize that the difference between alternative honors and Latin honors, aside from their criteria for eligibility, is often simply a matter of semantics in that they both offer a tiered recognition.

A practice which exists among a handful of identified programs is the incorporation of "other" criteria in addition to the GPA or class rank graduation honors criteria. While this research was not designed to identify the purpose of utilizing "other" criteria, one can infer that these programs view that the use of "other" criteria, in addition to the typical criteria, provides a commensurate level of recognition for doctorate level education. Among the programs analyzed, there appears to be a relatively even spread among the use of "other" criteria. The most common "other" criteria for eligibility of graduation honors was the enrollment in honors college, while the least common "other" criteria for eligibility was a required thesis. Honors college requirements vary from institution, but are typically available for outstanding students and provide opportunities such as mentored research projects, small class seminars, and access to distinguished faculty. ${ }^{14}$ It is also of note that programs added exclusion criteria, especially ethical conduct stipulations, which adds a level of non-academic performance to the honors designation.

Another interesting observation from the data of this research is that there was no significant difference between mean GPA cutoffs among programs utilizing Latin honors with and without "other" considerations. What this implies is that programs which utilize "other" considerations in addition to graduation honors, may be viewed as having more rigorous requirements, and therefore the graduation honors criteria at these programs makes obtaining honors a more select process.

From the perspective of the doctor of pharmacy student, one of the fundamental reasons to attain graduation honors would be to demonstrate academic success. Such demonstrations of success are often necessary as the market

Table 4. "Other" Graduation Honors Considerations Among Programs That Award Latin and/or Alternative Honors

Provision for course failure Provision for ethics violation Subject to faculty vote Honors college student

Research project requirement Thesis requirement for pharmacists becomes increasingly dense. However, it is unclear if the conferral of graduation honors translates to a competitive advantage in the job or post-doctoral education market, as it has yet to be substantiated by the literature. ${ }^{9-13,15}$ There is some evidence in medical education to suggest that a distinguished academic record results in obtaining more prestigious hospital residence placement. However, these studies are more than 50 years old and should be interpreted with caution. ${ }^{16,17}$ Ensor and colleagues report that grade point average (GPA) was among the top 5 highest scoring categories for invitation to interview for a pharmacy practice residency. Awards and scholarships were of note as well, while graduation awards were not considered. ${ }^{7}$ Of relevance is the varying calculation of grade point averages between institutions, which can impact the interpretation of a GPA across institutions. For example, some pharmacy programs include students' advanced pharmacy practice experience (APPE) rotation grades into final GPA calculations, while other programs do not grade APPE rotation but rather give a pass/fail mark.

There are also variations in the grading scales utilized by pharmacy schools. ${ }^{6}$ Although research has shown that the use of plus/minus grading does not impact mean GPA, this variability and GPA calculations may not be equivalent across institutions. ${ }^{7}$ If graduation honors criteria are not equivalent across institutions, the impact of receiving a graduation honor becomes uncertain. Most residency program directors consider the GPA of applicants. However, a survey of pharmacy program residency directors in 2014 ranked GPA lower than just five years ago. Also, the top three most valued characteristics of a residency applicant, according to that survey, were excellent letters of recommendation, strong letter of intent, and prior rotation experience with the applicant. ${ }^{9}$ The survey made no mention of graduation honors and also alluded to a decrease in the emphasis placed on GPA in decision making by postgraduate residency programs. ${ }^{8}$

The conferral of a doctor of pharmacy degree with honors of any type lacks a proven benefit beyond the individual receiving such degree. There has been no mention of recognizing this commendation as a decisive factor for either post-graduate residency programs or job placement. One potential reason for this may be that employers are experiencing difficulties distinguishing 


\section{American Journal of Pharmaceutical Education 2017; 81 (4) Article 69.}

how an honors graduate from one program would compare to an honors graduate from a second program, or to a program that lacks an honors program. With a rapidly growing market of recent graduates, as well as recent mergers in the community pharmacy setting, graduates will need novel ways to distinguish themselves in a more competitive market. Graduating with honors has the potential to be one of these methods, especially if wider adoption and valid comparisons between graduates of different programs can be made easily.

\section{CONCLUSION}

A majority of doctor of pharmacy programs do not award graduation honors, and there is no standard method of awarding graduation honors among the programs that do offer this distinction. Programs that are considering an addition of graduation honors to their list of commendation for learners who excelled in scholarship should first consider the apparent lack of impact on postgraduate residency or job placement and acknowledge that such honors may only afford personal value to the individual student. This research shows that among doctor of pharmacy degree programs, graduation honors are neither ubiquitous nor is the criteria utilized consistent. However, it is still a practice that many programs engage in. The establishment of universal or somewhat comparable criteria among US pharmacy programs may add value to the awarding of graduation honors.

\section{REFERENCES}

1. University of Connecticut. Latin honors. May 2015. http:// registrar.uconn.edu/latin-honors/. Accessed Feb 4, 2016 2. Albany Medical College. Requirements for graduation. Graduation objectives. $2016 \mathrm{http}: / / w w w . a m c . e d u / a c a d e m i c /$ undergraduate/Requirements.cfm. Accessed Feb 4, 2016 3. Cosgrove J. The impact of honors programs on undergraduate academic performance, retention, and graduation. $J$ Nat Colleg Honors Council. 2004 [cited 2015 Dec 2]. http://digitalcommons.unl. edu/nchcjournal/137.
4. Slavin C, Coladarci T, Pratt PA. Is student participation in an honors program related to retention and graduation rates? J Nat Colleg Honors Council. 2008. http://digitalcommons.unl.edu/ nchcjournal/66.

5. O'Neill P, Baxter CM, Morris J. Does awarding a medical degree with honours act as a motivator or demotivator to student learning? Med Educ. 1999;33(8):566-571.

6. Brandenburg S, Kruzick T, Lin CT, Robinson A, Adams LJ. Residency selection criteria: what medical students perceive as important. Med Educ Online. 2005;10(1):4383. http://med-ed-online. net/index.php/meo/article/view/4383. Date accessed: February 5, 2016.

7. Baker DM, Nemec EC. A survey of grading scale variations in doctor of pharmacy programs. Curr Pharm Teach Learn. 2014;6(2): 194-202.

8. Barnes KD, Buring SM. The effect of various grading scales on student grade point averages. Am J Pharm Educ. 2012;76(3):Article 41.

9. Ensor CR, Walker CL, Rider SK, Clemente EU, Ashby DM, Shermock KM. Streamlining the process for initial review of pharmacy residency applications: an analytic approach. Am J Health Syst Pharm. 2013;70(19):1670-1675.

10. Gohlke AL, Ray DB, El-Ibiary SY, Barletta JF. Characteristics of the ideal postgraduate year 1 pharmacy practice residency candidate: a survey of residency program directors. J Pharm Pract. 2014;27(1): 84-88

11. Granberry MC, Stiegler KA. Documentation and analysis of increased grade point averages at a college of pharmacy over 20 years. Am J Pharm Educ. 2003;67(3):Article 77.

12. Jungnickel PW. Grade-point averages and class rankings in evaluation of pharmacy residency applicants. Am J Health Syst Pharm. 2010;67(18):1500-1502.

13. Thompson DC, Nuffer W, Brown K. Characteristics valued by the pharmacy practice community when hiring a recently graduated pharmacist. Am J Pharm Educ. 2012;76(9):Article 170.

14. Duquesne University. Why students choose honors. http://www. duq.edu/academics/honors-college/why-students-choose-honors. Accessed Feb 4, 2016.

15. Pharmacist Demand Indicator. National pharmacist demand average response. December 2016. http://pharmacymanpower.com/. Accessed Feb 4, 2016.

16. Fowell S. An honours degree in medicine: what does it mean? Med. Educ. 1999;33(7):476-477.

17. Last JM, Martin FM, Stanely GR. Academic record and subsequent career. Proc R Soc Med. 1967;60(8):813-816. 